\title{
The use of rye, oat and triticale straw as fillers of natural rubber composites
}

\author{
Marcin Masłowski ${ }^{1}$ (D) Justyna Miedzianowska' ${ }^{1}$ Anna Strąkowska ${ }^{1} \cdot$ \\ Krzysztof Strzelec $^{1} \cdot$ Małgorzata Iwona Szynkowska $^{2}$
}

Received: 5 July 2017 / Revised: 2 February 2018/Accepted: 6 February 2018/

Published online: 12 February 2018

(C) The Author(s) 2018. This article is an open access publication

\begin{abstract}
Up to date, there are no evident research works carried out to improve and verify the physical, mechanical, barrier and damping properties of bioelastomer composites with addition of straw. Moreover, the problem of improving the reuse of straw is now demanding attention in the major cereal-growing areas of the world. The aim of this study was to receive knowledge of characteristic and producing multifunctional elastomer biocomposite filled with straw. Rye, oat and triticale were found to be active fillers improving wide range of rubber composites functional properties like: static mechanical, damping, barrier properties and hardness. The use of straw as a filler also increased cross-linking density. Dynamic-mechanical analysis indicates the presence of strongly developed secondary structure of examined fillers in vulcanizates. Moreover, all of the vulcanizates proved to be resistant to thermo-oxidative degradation. The application of straw as a filler allowed obtaining composites with lower value of oxygen index, that reflecting higher tendency of smoke generation. Introducing the straw into polymer matrix reduced the manufacturing costs of composites through the use of a significant amount of inexpensive and renewable filler. Furthermore straw fillers modify natural rubber, obtaining high-performance materials with meaningly enhanced applications.
\end{abstract}

Marcin Masłowski

marcin.maslowski@p.lodz.pl

1 Institute of Polymer and Dye Technology, Lodz University of Technology, 12/16

Stefanowskiego Street, 90-924 Lodz, Poland

2 Institute of General and Ecological Chemistry, Lodz University of Technology, 116

Zeromskiego Street, 90-924 Lodz, Poland 


\section{Introduction}

Green composites are gaining notice because of the increase in environmental consciousness and regulations [1]. Specifically, interest in lignocellulosic-filled polymer composites has increased because of their advantages, including reduced cost and improved mechanical properties. Green composites are biocomposites where both matrix and reinforcement derive from renewable resources. The term eco-friendly composite so-called green composites and biocomposites are usually used to describe a composite material with environmental and ecological advantages over the conventional composites. What is more, there is simultaneous and growing interest in developing the use of bio-based products that can reduce the dependence on fossil fuel and move to a sustainable materials basis [2, 3]. This particular situation provides unique bionanocomposites possessing outstanding properties, which have been never found in the conventional composites [4]. Therefore, biobased nanocomposites are the next generation of materials for the future [5]. At present, only a few bio-based polymers among those developed have been studied and applied as the matrix in green composites. However, the broad range of biobased polymers that are commercially available is expected to stimulate further investigations on their potential use as matrices in green composites [6].

An eco-composite may contain either natural reinforcement filler or a natural polymer matrix, or it can be a combination of natural reinforcement filler and a biodegradable polymer matrix [7] like natural rubber. Natural rubber (NR) is an elastomer that is originally derived from a milky colloidal suspension, or latex, found in the sap of some plants. Rubber composites are mainly used for making ropes, hoses, belts, and mats [8]. NR has already been studied as a matrix for bionanocomposites with chitin whiskers [9], cellulose whiskers extracted from Syngonanthus nitens (Capim Dourado) [10], and rachis of palm tree [11]. It is possible to obtain fillers from different renewable resources depending on their biological origin, e.g., cellulose and starch [12], but main research is dedicated to cellulose whiskers, as this polymer is the most abundant on earth. Regarding biocomposites, most studies found in the literature use cellulose as simple "filler", which, in some cases, contributes to enhance the rigidity but mostly embrittles the polymer. The study of cellulosic particles as a reinforcing phase in composite has started 20 years ago [13] and still is a topical subject.

Cellulose is the main component of vegetable fibers and the elementary unit of a cellulose macromolecule is anhydro D-glucose which contains three hydroxyl $(-\mathrm{OH})$ groups. Unlike the traditional engineering fibers, e.g., glass and carbon fibers, and mineral fillers, these lignocellulosic fibers are able to impart benefits such as low density, less machine wear during processing than is generated by mineral reinforcements, no health hazards, and a high degree of flexibility. Natural fibers impart high specific stiffness and strength to the composite, they have a desirable fiber aspect ratio, are biodegradable, and they are readily available from natural sources. Most importantly, they have a low cost per unit volume. It should also be noted that the hollow nature of vegetable fibers may impart acoustic insulation or damping properties to certain products. One difficulty relating to the use of fibers in 
composites is the lack of good adhesion to most polymeric matrices. The hydrophilic nature of natural fibers adversely affects adhesion to a hydrophobic matrix, and as a result, strength may be lost [6].

Agriculture plays a significant role in the world to feed the growing human population. Therefore, land for crop production will be used more intensively for human food production, and consequently, animal production will rely on feeding the by-products from the food produced for human consumption [14]. For many centuries, straw was valued as the most useful by-product of cereal production and it has been used for feeding livestock, bedding, growing mushrooms, and so on. Straw is the dried, above ground, remains of physiologically mature plants from which seeds have been harvested. As small grain plants become physiologically mature, nutrient-rich concentrates such as fat, starch, and protein are accumulated in the seeds. Consequently, less valuable nutrients like cellulose, hemicellulose, and lignin remain in the straw. In general, straw is comprised of plant stem and leaf fractions. However, because of non-selective processing inherent in modern harvesting equipment, straw can contain other plant parts. Leaves are typically thin flat plant organs which specialize in photosynthesis. Stems are above-ground plant structures that support leaves and flowers. Nodes are the part of the stem where leaves are attached and internodes are areas between nodes on a stem [15]. Ratios of botanical fractions vary with species, variety, and growing environment. In addition to function and structure, botanical fractions differ in chemical composition. Straw stems, leaves, nodes and internodes are different in chemical composition in components such as protein, cellulose, hemicellulose, and lignin. Among botanical fractions of wheat and barley, internodes are the highest in lignin. Leaves and nodes have the greatest protein content. Hemicellulose concentration is the highest in nodes and cellulose is the highest in internodes [16].

With the development of science and technology in the recent decades, especially with the exploitation of petroleum, straw is regarded as little more than an embarrassing companion to the grain crop. Farmers in many of the chief cerealgrowing countries of the world burn or plough the straw into the field directly as a fertilizer. However, as petroleum is currently one of the most important natural resources and a raw material for the synthesis of various chemicals, a serious of issues has arisen, such as the diminishing world reserves of petroleum market. Especially, the problem of global warming requires severe reductions in the use of fossil fuel [17]. In addition, the straw burning should be avoided, as it causes serious environmental pollution. These problems have led researchers to pay attention to the value of biomass, which is both sustainable and $\mathrm{CO}_{2}$-neutral. Agricultural crop residues, such as straws of wheat, barley, rice, maize, oats, rye, and cotton, as well as sugarcane bagasse and other residues, represent an enormous underutilized energy resources, which has a great potential as feed for ruminants and also as raw materials for paper, chemicals, polymers, and other technical products [18]. Because of the enormous quantity of straw, utilization of straw to the utmost extent is now demanding attention in the major cereal-growing areas of the world.

Up to date, there are no evident research works carried out to improve and verify the physical, mechanical, barrier, and damping properties of bioelastomer composites with addition of straw. Study designed to characterize the properties of 
thermoplastic polymers containing agricultural crop residues is focused mainly on fibers and does not cover the end of cereal waste management problem. In a word, before utilizing it well, we should have a good understanding of straw and elastomer technology. This research work was lead to reach the goal of knowing the characteristic and producing multifunctional elastomer (natural rubber) biocomposites filled with straw. With the development of elastomer and straw chemistry, it could reasonably believe that rye, oat, and triticale can play an important role in human lives in the future with performance benefits.

\section{Experimental}

\section{Materials}

Natural rubber (NR)-RSSI, cis-1,4-polyisoprene, density $0.93-0.988 \mathrm{~g} / \mathrm{cm}^{3}$ was provided by Torimex Chemicals. It was vulcanized with the conventional sulfur cure system which consists of: sulfur, microsized zinc oxide, 2-mercaptobenzothiazole, and stearin. Fillers: rye, oat, and triticale straws were collected from local farms. Dried straw was ground into fine powder using a ball mill (SPEX SamplePrep 8000D Mixer/Mill).

Composition of typical elastomer mixture: NR rubber (100 phr), sulfur ( $2 \mathrm{phr}$ ), 2-mercaptobenzothiazole ( $2 \mathrm{phr})$, zinc oxide ( $5 \mathrm{phr})$, stearin (1 phr), and fillers$10,20,30,40,50 \mathrm{phr}$.

\section{Methods}

Elastomer mixtures based on natural rubber filled with rye, oat, and triticale straw were prepared by a Brabender measuring mixer N50. Different types of straw were mixed with the rubber together with the vulcanization system (temp. $50-60{ }^{\circ} \mathrm{C}$, rotor speed range $40 \mathrm{~min}^{-1}$, time of the process $15 \mathrm{~min}$ ). Next, two-roll mill was used to obtain blends sheets. Then, the mixtures were cured at $160{ }^{\circ} \mathrm{C}$, at $15 \mathrm{MPa}$ pressure for $15 \mathrm{~min}$.

The kinetic characteristic of rubber vulcanization as well as rheometric properties of compounds were studied using MonTech DRPA 300 Rheometer (ISO 6502).

The mechanical properties were examined by static materials testing machine Zwick, according to ISO 37 standards.

Dynamic-mechanical analysis (DMA) was studied with the application of ARES Rheometer (plate-plate system, plate diameter: $20 \mathrm{~mm}$; gap $2 \mathrm{~mm}$ ). DMA test parameters: temperature: $25{ }^{\circ} \mathrm{C}$, sample deformation rate: $10 \mathrm{rad} / \mathrm{s}$, stress: from 0.1 to $150 \%$, test force: $5 \mathrm{~N}$. The Payne effect ( $\left.\Delta G^{\prime}[\mathrm{MPa}]\right)$ values of the composites have been calculated based on Eq. 1:

$$
\Delta G^{\prime}=G_{\min }^{\prime}\left(\lim 10^{-1}\right)-G_{\max }^{\prime}(\infty),
$$

where: $G_{\min }^{\prime}\left(\lim 10^{-1}\right)$ - a composite storage modulus determined under the deformation of $10^{-1} \%$; $G_{\min }^{\prime}(\infty)$-a composite storage modulus determined under the max deformation. 
The cross-linking density of cured samples was calculated by authors based on rapid solvent-swelling measurements (in toluene) using the Flory-Rehner equation. Elastomer-solvent interaction parameters are as follows:

$$
\mu_{0}=0.478, \quad \beta=0.228 \text {. }
$$

The cross-link density of the vulcanizates was determined by equilibrium swelling in toluene, based on the Flory-Rehner [20] (Eq. 3):

$$
\gamma_{\mathrm{e}}=\frac{\ln \left(1-V_{\mathrm{r}}\right)+V_{\mathrm{r}}+\mu V_{\mathrm{r}}^{2}}{V_{0}\left(V_{\mathrm{r}}^{\frac{1}{3}}-\frac{V_{\mathrm{r}}}{2}\right)} .
$$

Here, $\gamma_{e}$ - the cross-link density $\left(\mathrm{mol} / \mathrm{cm}^{3}\right), V_{0}$ - the molecular volume of solvent $\left(106.7 \mathrm{~cm}^{3} / \mathrm{mol}\right), \mu$-the Huggins parameter of the NR-solvent interaction, which was calculated from Eq. 4:

$$
\mu=\mu_{0}+\beta \cdot V_{\mathrm{r}}
$$

where $\mu_{0}$ - the parameter determine of non-cross-linked polymer/solvent relations, $\beta$ - the parameter determine of cross-linked polymer/solvent relations, and $V_{\mathrm{r}}$ - the volume fraction of elastomer in the swollen gel (Eq. 5):

$$
V_{\mathrm{r}}=\frac{1}{1+Q_{\mathrm{w}} \frac{\rho_{\mathrm{r}}}{\rho_{\mathrm{s}}}},
$$

where $Q_{\mathrm{w}}$-weight of equilibrium swelling, $\rho_{\mathrm{r}}$ - density of rubber $\left(0.988 \mathrm{~g} / \mathrm{cm}^{3}\right)$, and $\rho_{\mathrm{s}}$ - density of solvent $\left(0.86 \mathrm{~g} / \mathrm{cm}^{3}\right)$.

The thermo-oxidative degradation of the vulcanizates was performed at a temperature of $70{ }^{\circ} \mathrm{C}$ for $336 \mathrm{~h}$. To estimate the resistance of the samples to aging, their mechanical properties after aging were determined and compared with the values obtained for vulcanizates before the aging process. The aging factor $(K)$ was calculated as the numerical change in the mechanical properties of the samples upon aging (Eq. 6), where TS is the tensile strength of the vulcanizates, and EB is the elongation at break:

$$
K=\left(\mathrm{TS} \cdot E_{\mathrm{b}}\right)_{\text {afteraging }} /\left(\mathrm{TS} \cdot E_{\mathrm{b}}\right)_{\text {beforeaging }},
$$

where: $E_{\mathrm{b}}$-elongation at break; TS-tensile strength.

Composites hardness was determined according to ISO 868 standard using a Shore type A Durometer (Zwick/Roell) and the presented results are average from random ten points for each sample.

The flammability of vulcanizates was performed by the method of oxygen index (OI) using $50 \times 10 \times 4 \mathrm{~mm}$ samples, at a constant nitrogen flow rate in a measurement column $(D=75 \mathrm{~mm})$ amounting to $40 \pm 2 \mathrm{~mm} \times \mathrm{s}^{-1}$. The concentration of oxygen was selected, so that the sample could be completely burned within $180 \mathrm{~s}$. The sample tip was ignited for $5 \mathrm{~s}$ by means of a gas burner supplied with propane-butane mixture. The value of OI was calculated from Eq. 7: 


$$
\mathrm{OI}=\frac{\left[\mathrm{O}_{2}\right]}{\left[\mathrm{O}_{2}\right]+\left[\mathrm{N}_{2}\right]} \cdot 100 \%,
$$

where: $\left[\mathrm{O}_{2}\right]$ is the final oxygen concentration, at which a sample is burned within $180 \mathrm{~s} ;\left[\mathrm{N}_{2}\right]$ is a constant flow rate of nitrogen.

Barrier properties were evaluated based on the through-plane air permeability of composites using manometric method in accordance with the ASTM standard D1434. The tests were conducted using atmospheric air at room temperature. Measurement of the barrier properties is based on a pressure difference in the chambers on both sides of the sample.

Damping properties of elastomer composites were determined under the influence of compressive stress using a ZWICK ZMARTPRO 1435 (Zwick/Roell). The relative damping value was calculated by Eq. 8:

$$
T_{\tau \mathrm{w}}=\frac{\Delta W_{\mathrm{i}}}{W_{\mathrm{ibel}}} \cdot 100 \%,
$$

where: $T_{\tau \mathrm{w}}$-relative damping; $\Delta W_{\mathrm{i}}$-the difference between the compression work and the work during reducing the compressive stresses; $W_{\text {ibel }}$ - compression work

The average size of straw was determined using a Zetasizer NanoS90 apparatus (Malvern). The size of particles in water $(0.04 \mathrm{~g} / \mathrm{l})$ and paraffin oil dispersion $(0.04 \mathrm{~g} / \mathrm{l})$ were measured based on the dynamic light scattering DLS method.

The oil absorption parameter (DBPA) of fillers was measured according to ASTM D2414 using Absorptometer C (Brabender). Process parameters: sample weight $20 \mathrm{~g}$ and titration rate $4.0 \mathrm{ml} / \mathrm{min}$. The oil used in this study was dibutyl phthalate DBP.

The morphology of pure straws and selected composites samples (10 phr straw) was analyzed by means of the SEM, a scanning electron microscopy with field emission S-4700 Hitachi (Japan). Before the SEM measurements, the samples were placed on carbon plasters and coated with the use of carbon target by the Cressington $208 \mathrm{HR}$ system. The accelerating voltage was $25 \mathrm{kV}$.

Determination content of cellulose and lignin was analyzed according to previously reported methods [19].

The principle of determining the cellulose content is based on the dissolution of lignin contained in the lignocellulosic material with a mixture of acetylacetone and dioxane acidified with hydrochloric acid. Three measurements were carried out for each of the materials tested. The weight of shredded rape straw weighing $1 \pm 0.0001 \mathrm{~g}$ was placed in a round bottom flask, adding a mixture of: $6 \mathrm{ml}$ of acetylacetone, $2 \mathrm{ml}$ of dioxane and $1.5 \mathrm{ml}$ of hydrochloric acid. The reaction flask was heated for $40 \mathrm{~min}$ in a heating can, and then, $40 \mathrm{ml}$ of methyl alcohol was added, and the entire contents of the flask were separated. The precipitate was washed successively: $100 \mathrm{ml}$ of methyl alcohol, $40 \mathrm{ml}$ of distilled water, $40 \mathrm{ml}$ of dioxane, $40 \mathrm{ml}$ of methyl alcohol, and $40 \mathrm{ml}$ of ethyl ether. The cellulose content was calculated based on the weight difference (dried to constant mass at temperature).

The principle of determining the content of acid-insoluble lignin consists in converting carbohydrate compounds with soluble sugars with sulfuric acid. Samples 
of test material weighing $1 \mathrm{~g}$ were placed in $100 \mathrm{ml}$ beakers, followed by the addition of $15 \mathrm{ml} 72 \% \mathrm{H}_{2} \mathrm{SO}_{4}$. The mixtures thus prepared were allowed to stand for $2 \mathrm{~h}$, stirring every $15 \mathrm{~min}$. The content of each beaker was then transferred to a $1000 \mathrm{ml}$ flask and made up to $575 \mathrm{ml}$ with distilled water to give a $3 \%$ solution. After which the solution was boiled for $4 \mathrm{~h}$. After filtration of the precipitate, washing with distilled water and drying to a constant mass, the acid-insoluble lignin content was calculated on the basis of the mass difference of the sample before and after the extraction process.

\section{Results and discussion}

\section{Characteristic of the fillers}

\section{The average size and oil absorption of straw fillers}

One of the most important parameters to describe the filler is particle size. Too large particles can concentrate stresses and lead to decreased strength of the materials, while too small particles are difficult to disperse and reveal a high tendency to agglomeration with agglomerates of different sizes and structures. The particle size influences the activity of the filler, which is one of the factors determining the reinforcing effect of filler. Another parameter characterizing filler is DBPA number. The empty space (void volume) between the aggregates and agglomerates can be expressed as the volume of dibutyl phthalate (DBP) absorbed by a given amount of filler, which is reflected in the number of DBPA value. This is the technique used to determine the amount of filler to provide structural information about the structure and porosity of the filler particles. Higher DBPA oil absorption values correspond to higher structures. In general, increasing the surface area (decreasing particle size) provides lower resilience and higher tensile strength, abrasion, resistance, tear resistance, and hysteresis. Table 1 presents the results of the particle size of straw fillers in different media (water and paraffin oil) and DBPA oil absorption numbers.

Elastomers have a hydrophobic nature; therefore, the size of the particles was measured in a liquid hydrophobic medium-paraffin oil, which was chosen as the model for an elastomer matrix. Analyzing the results collected in Table 1, it should be noted significant difference in the size of the fillers agglomerates in water and paraffin oil. The average agglomerates sizes measured in water are lower than in

Table 1 Particle size of straw fillers in different media (water and paraffin oil) and DBPA oil absorption values

\begin{tabular}{llll}
\hline $\begin{array}{l}\text { Filler } \\
\text { type }\end{array}$ & $\begin{array}{l}\text { Average size of filler } \\
\text { agglomerates (water) }[\mu \mathrm{m}]\end{array}$ & $\begin{array}{l}\text { Average size of filler } \\
\text { agglomerates (paraffin oil) } \\
{[\mu \mathrm{m}]}\end{array}$ & $\begin{array}{l}\text { DBPA (dibutyl phthalate } \\
\text { absorption) }[\mathrm{ml} / 100 \mathrm{~g}]\end{array}$ \\
\hline Rye & $1.063 \pm 0.025$ & $5.547 \pm 0.051$ & 134 \\
Oat & $1.050 \pm 0.036$ & $4.038 \pm 0.034$ & 129 \\
Triticale & $1.084 \pm 0.044$ & $5.188 \pm 0.031$ & 131
\end{tabular}


paraffin oil. Filler dispersion in paraffin oil was significantly worse than in waterstraw particles which exhibit an increased tendency to aggregate or even agglomerate. The sizes of the agglomerates in the paraffin oil were even 5 times higher than in water. DBPA oil adsorption values found to be similar for all tested types of fillers and were in the range of 129-134 ml/100 g. This indicates that rye, oat, and triticale represent typical semi-reinforcing character.

However, DLS analysis may only characterized the dynamic size of the welldispersed part of the fillers, but not the whole-milled straws that are incorporated in the rubber compositions. The straw fibers of $100 \mu \mathrm{m}$ in length may precipitate in the cuvette or may exceed the proper measuring range of DLS. To illustrate the structure of the fillers and the morphology of the composites produced, scanning electron microscopy measurements were performed. Microscopy images of fillers and selected vulcanizates were given in Figs. 1, 2, and 3. The filler particles exhibit inhomogeneities in size and shape. Mostly, they resemble fibers with the size range from several dozen to several hundred microns.
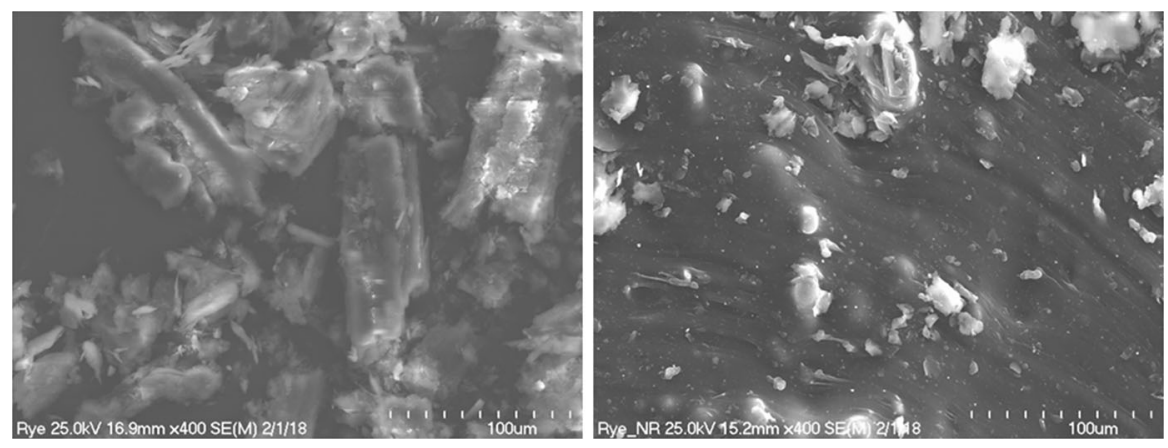

Fig. 1 SEM images of rye filler (left) and vulcanizate containing 10 phr rye straw (right)
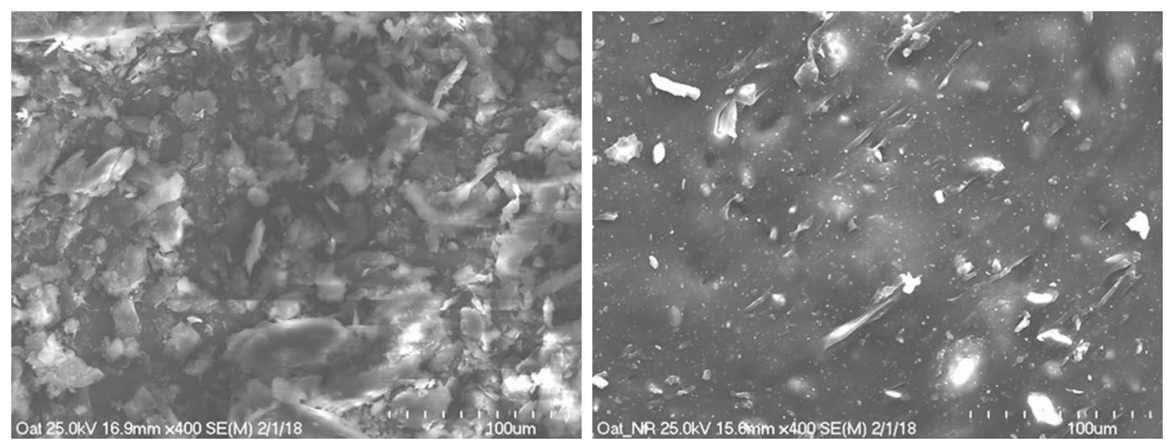

Fig. 2 SEM images of oat filler (left) and vulcanizate containing $10 \mathrm{phr}$ oat straw (right) 

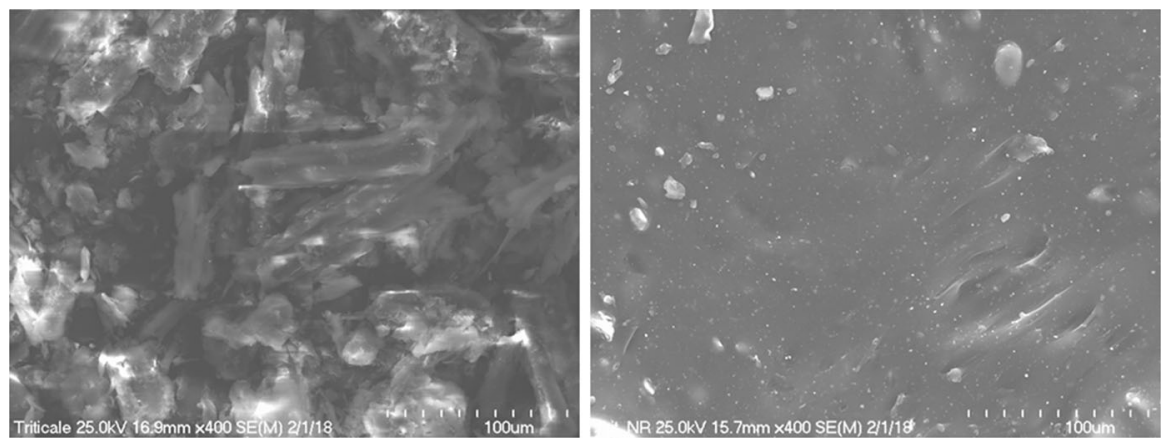

Fig. 3 SEM images of triticale filler (left) and vulcanizate containing $10 \mathrm{phr}$ triticale straw (right)

\section{Lignin and cellulose content}

Rye, oat, and triticale are all lignocellulosic materials. Cellulose provides high stiffness and tensile strength of natural fibers, while lignin improves their compressive strength. The addition of lignocellulose filler may favorably influence the properties of the composite. The results of determination of the cellulose and lignin content in different type of straw are given in Table 2.

From the data compiled it appears that, for three different straws, cellulose content values vary from $30 \%$ for oat, by nearly $35 \%$ for rye, and up to $40 \%$ for triticale. The differences oscillate in the range of $20 \%$, which may have an influence on the properties of biocomposites. The highest content of lignin, similarly as in cellulose analysis, revealed to triticale straw. The remaining tested varieties contained $30 \%$ of lignin in rye and $23 \%$ in oat straw.

\section{Characteristic of composites}

\section{Rheometric properties of natural rubber mixtures}

Rheometric properties of the polymer mixtures were determined from the increase in torque during the cross-linking process together with the curing time. Characterization of these parameters provides preliminary information on the effect of filler on the properties and curing behavior of the elastomer composites on the filler's ability to create a "structure" in the elastomer. Increase in the minimum and the maximum torque due to the action of the filler is an indirect measure of:

Table 2 Content of cellulose and lignin in rye, oat, and triticale straw

\begin{tabular}{lcc}
\hline Filler type & Cellulose content [\%] & Lignin content [\%] \\
\hline Rye straw & $37.4 \pm 2.4$ & $30.8 \pm 1.2$ \\
Oat straw & $31.7 \pm 1.8$ & $23.6 \pm 1.9$ \\
Triticale straw & $39.6 \pm 1.1$ & $32.9 \pm 1.4$ \\
\hline
\end{tabular}


- the hydrodynamic effect,

- and/or "structure" with a high filler content,

- and/or increase in the cross-linking density.

Introduction to polymer matrix of the solid-phase rigid and not deformable causes a hydrodynamic effect appearance. Therefore, the internal stress of the polymer network is greater than those from the outside, resulting in an independent contribution to the deformation torque or the Young's modulus. Figures 4, 5 represent rheometric properties of biocomposites containing straw fillers (rye, oat, and triticale) in different contents ( $0-50 \mathrm{phr})$.

Increase in torque during cross-linking $(\Delta M)$ is a characteristic of the cured rubbers and represents the degree of chemical cross-linking. The reaction of rubbers with curing agents is merely one factor influencing the cross-linking process. Other factors include the chemical bonding of rubbers with the functional groups on the filler surface or physical interactions between the matrix and the filler, which increase the overall degree of curing. This interaction implies that the state of cure of rubber compounds might change in the presence of the filler. Applied fillers have a positive impact on the kinetics characteristics of NR mixtures vulcanization. All types of straw seem to be an active biofillers, showing an influence on the torque increment during cross-linking. Regardless of the straw type, $\Delta M$ values increase with the higher fillers content. The addition of the filler presumably reflected in the hydrodynamic effect. Consequently, formed stress in elastomeric network is greater than those applied during deformation. It is probably that the torque increment of compositions may be also a reflection of the increase in vulcanizates cross-linking density.

The addition of the filler slightly affected the $t_{\mathrm{w}}$ values, as illustrated in Fig. 5. The use of lignocellulosic material resulted in a reduction of curing time in

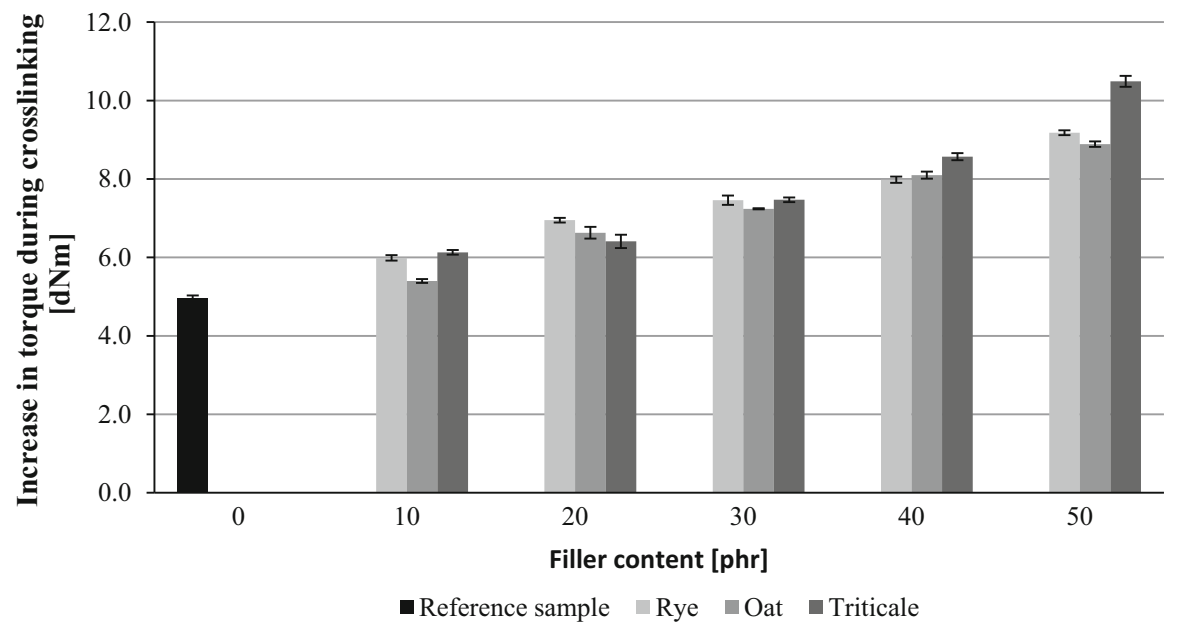

Fig. 4 Influence of different straw fillers content on the increase in torque during cross-linking of the rubber mixtures 


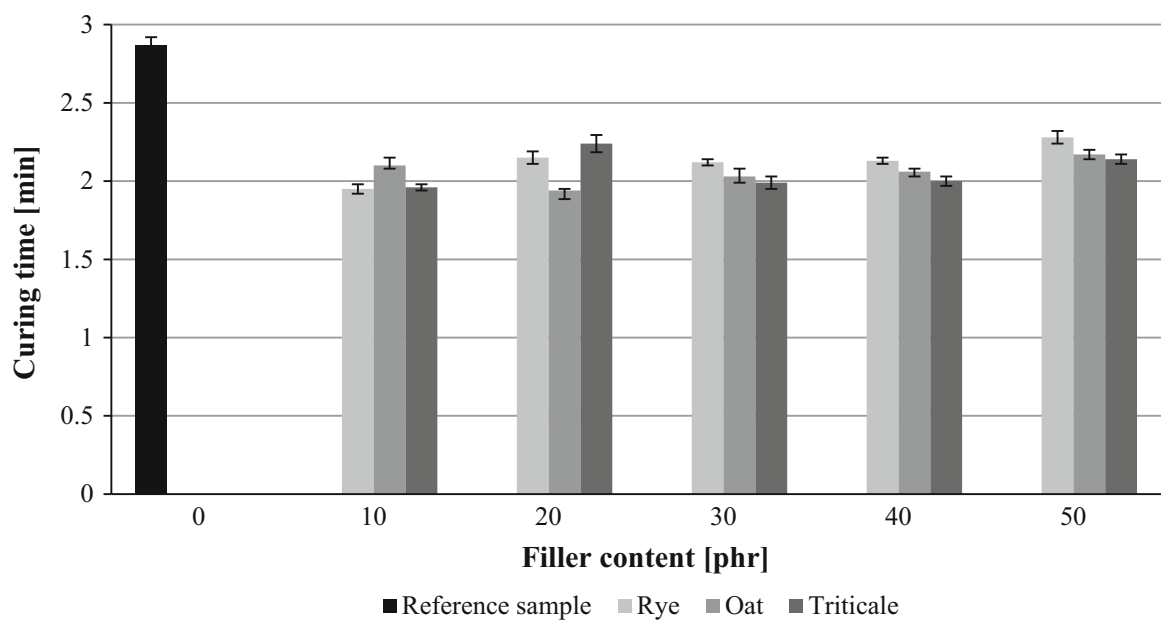

Fig. 5 Influence of different straw fillers content on the curing time of the rubber mixtures

comparison with reference sample approximately from 3 to 2 min regardless of used straw.

\section{Mechanical properties of natural rubber composites}

Static mechanical properties and cross-linking density Physical properties of vulcanizates are the resultant of many parameters, which depend on the amount and type of filler and its characteristic features, which we have described extensively in the filler characteristics section. The type of rubber and its degree of cross-linking, and therefore, the properties of the medium in which the filler is dispersed are equally important. A layer of immobilized rubber is formed around the filler, which has a significant influence on the mechanical properties of the composites obtained. Rubber is formed as a result of physical-chemical interactions; however, the exact mechanism of its formation is not fully understood. Regardless of the theory of bound rubber formation, it is assumed that the mechanical properties of rubber composites depend on interfaces at the interface) in the filler particle systemelastomeric matrix. A number of publications prove that the tensile strength of polymers remains in close dependence on the adhesion between the filler and the medium and the mechanism of stress transfer in the filler-polymer system. According to the theory according to Bueche [20], strong filler-polymer interactions behave like physical network nodes and act as additional elements in the system's network. As a result of the increase in the overall cross-link density due to the presence of the filler in the polymer, the strength of the network, as a consequence, also the stiffness of the composites increases with the increase of the filler-polymer interactions. On the other hand, exaggeratedly strong interactions can directly contribute to the loss of elasticity of the polymer at the interface, resulting in a reduction in the elongation at break of the filled composites. Therefore, many 
changes in mechanical properties are attributed to a change in the obtained crosslink density results.

The use of biofiller entails economic benefits, but it is also important to get the material competitiveness among commercially available products. Currently, the aim of many studies is to obtain composites with unique functional properties. The use of new technological additives requires to check their influence on mechanical properties. Effect of different straw fillers particles (rye, oat, and triticale) on the natural rubber behavior was estimated based on the mechanical properties (tensile strength and elongation at brake), hardness, and cross-linking density of the vulcanizates. The results are given in Table 3.

The use of straw as a filler raised cross-linking density of the composites when compared with unfilled system, it was reflected previously by the rheometric properties. Moreover, with the increase of the filler content, an increase of the network nodes concentration in obtained vulcanizates was observed. Therefore, the increase in the value of $v_{\mathrm{e}}$ (for all vulcanizates filled with rye, oat, and triticale compared to the reference sample) indicates that the interaction at the interface of the elastomer-filler also increases, which manifest itself into improved mechanical properties. Increased activity of fillers was confirmed by improved mechanical properties of biocomposites that is in a good agreement with mentioned above studies on rheological properties of the mixtures and cross-linking density. Such changes of mechanical properties result in an increased stress at $100 \%$ elongation

Table 3 Mechanical properties, hardness, and cross-linking density of the vulcanizates filled with different content and type of straw

\begin{tabular}{|c|c|c|c|c|c|c|}
\hline Filler type & $\begin{array}{l}\text { Filler content } \\
{[\mathrm{phr}]}\end{array}$ & $\begin{array}{l}\mathrm{SE}_{100} \\
{[\mathrm{MPa}]}\end{array}$ & $\begin{array}{l}E_{\mathrm{b}} \\
{[\%]}\end{array}$ & $\begin{array}{l}\text { Hardness } \\
{ }^{\circ} \text { Sh A }\end{array}$ & $\begin{array}{l}\mathrm{TS} \\
{[\mathrm{MPa}]}\end{array}$ & $\begin{array}{l}v_{e} \cdot 10^{-5} \\
{\left[\mathrm{~mol} / \mathrm{cm}^{3}\right]}\end{array}$ \\
\hline Reference sample & - & $0.82 \pm 0.02$ & $691 \pm 12$ & $26.2 \pm 0.5$ & $11.5 \pm 0.4$ & $1.35 \pm 0.04$ \\
\hline \multirow[t]{5}{*}{ Rye } & 10 & $1.00 \pm 0.03$ & $650 \pm 25$ & $28.1 \pm 0.7$ & $16.8 \pm 0.6$ & $2.17 \pm 0.05$ \\
\hline & 20 & $1.30 \pm 0.08$ & $638 \pm 19$ & $28.5 \pm 0.6$ & $13.5 \pm 0.5$ & $2.45 \pm 0.06$ \\
\hline & 30 & $1.64 \pm 0.07$ & $590 \pm 8$ & $30.3 \pm 0.6$ & $12.4 \pm 0.3$ & $2.57 \pm 0.09$ \\
\hline & 40 & $1.86 \pm 0.07$ & $534 \pm 9$ & $38.1 \pm 0.9$ & $9.1 \pm 0.5$ & $2.59 \pm 0.10$ \\
\hline & 50 & $1.92 \pm 0.08$ & $481 \pm 15$ & $41.9 \pm 0.6$ & $6.2 \pm 0.2$ & $2.77 \pm 0.11$ \\
\hline \multirow[t]{5}{*}{ Oat } & 10 & $1.04 \pm 0.02$ & $676 \pm 10$ & $27.2 \pm 0.7$ & $16.6 \pm 0.9$ & $2.01 \pm 0.02$ \\
\hline & 20 & $1.30 \pm 0.05$ & $624 \pm 8$ & $32.2 \pm 0.7$ & $15.0 \pm 0.5$ & $2.58 \pm 0.01$ \\
\hline & 30 & $1.69 \pm 0.03$ & $538 \pm 9$ & $34.8 \pm 1.1$ & $11.3 \pm 0.6$ & $2.73 \pm 0.07$ \\
\hline & 40 & $1.91 \pm 0.05$ & $517 \pm 4$ & $44.1 \pm 0.6$ & $10.8 \pm 0.5$ & $3.11 \pm 0.01$ \\
\hline & 50 & $2.23 \pm 0.11$ & $485 \pm 12$ & $46.9 \pm 0.4$ & $8.5 \pm 0.6$ & $3.13 \pm 0.15$ \\
\hline \multirow[t]{5}{*}{ Triticale } & 10 & $1.09 \pm 0.09$ & $657 \pm 12$ & $29.2 \pm 0.8$ & $17.5 \pm 0.8$ & $2.24 \pm 0.07$ \\
\hline & 20 & $1.32 \pm 0.02$ & $637 \pm 12$ & $29.8 \pm 1.0$ & $14.2 \pm 0.2$ & $2.27 \pm 0.09$ \\
\hline & 30 & $1.59 \pm 0.03$ & $563 \pm 12$ & $31.8 \pm 1.2$ & $10.2 \pm 0.3$ & $2.68 \pm 0.06$ \\
\hline & 40 & $2.08 \pm 0.06$ & $524 \pm 9$ & $46.5 \pm 0.6$ & $9.6 \pm 0.3$ & $3.24 \pm 0.03$ \\
\hline & 50 & $2.02 \pm 0.08$ & $476 \pm 13$ & $49.2 \pm 0.8$ & $6.3 \pm 0.3$ & $3.40 \pm 0.11$ \\
\hline
\end{tabular}

$S E_{100}$ stress at $100 \%$ elongation, $E_{b}$ elongation at break, $T S$ tensile strength, $v_{e}$ the cross-linking density of the vulcanizates 
and tensile strength of the vulcanizates. The tensile strength results are also shown in Fig. 6.

In the case of vulcanizates filled with rye and oat straw, the tensile strength was unimpaired to $30 \mathrm{phr}$ content of filler and for triticale straw to $20 \mathrm{phr}$ in the comparison with the reference vulcanizate. Regardless of the type of filler, the greatest TS value was obtained for the straw content of $10 \mathrm{phr}$. The highest tensile strength values were obtained for sample containing $10 \mathrm{phr}$ triticale straw; this may correlate with the cellulose content in this type of straw. However, it is also worth mention that the differences between other biofillers were unsignificant. Elongation at break oscillates at a similar level in the range of 470-670\% for all fillers' type.

The use of straw as a polymer additive resulted in an increase of hardness compared with the unfilled vulcanizate. Hardness values of all the filled composites increase with increasing the content of straw and were in the range of $27^{\circ}-50^{\circ}$ Shore A.

\section{Damping properties under the influence of compression stress}

The essential characteristic of the elastic elements is their high deformability in the direction of the load (force or torque), several times higher than other materials. The elastic elements have the ability for accumulation of potential energy, taking over vibration and mitigate the impact. Elastic elements can also dissipate energy.

The presented data (Fig. 7) indicate that all composites exhibit good damping properties. Applying of rye, oat and triticale fillers considerably increased the relative damping values of natural rubber vulcanizates. What is worth mention the differences between damping properties of composites obtained are not significant despite the type of straw used. Moreover, with higher content of the fillers, relative damping values also increase.

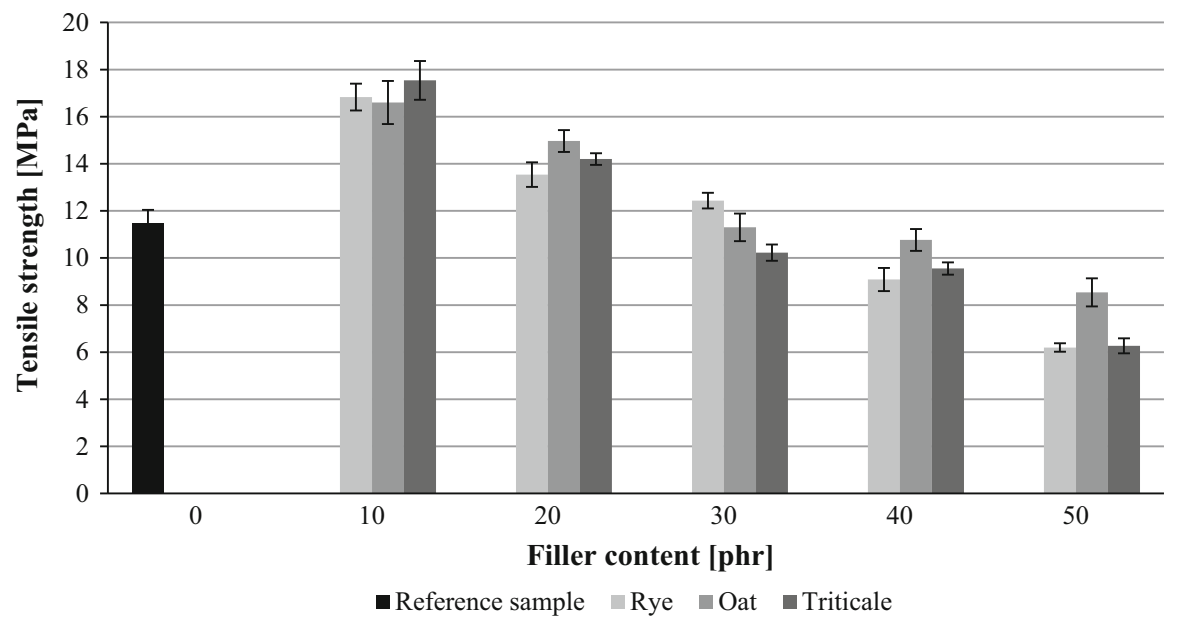

Fig. 6 Influence of different straw fillers content on the tensile strength of the composites 


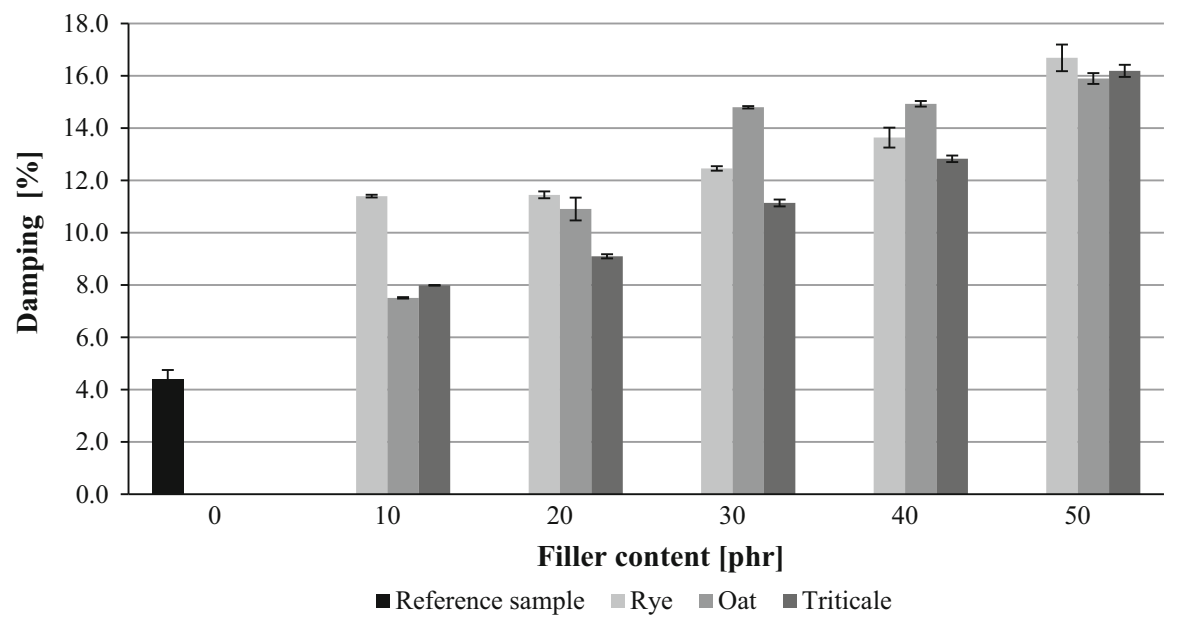

Fig. 7 Influence of different straw fillers content on the damping of the composites

\section{Flammability of biocomposites}

At present, the oxygen index is one of the most widely used methods of evaluation flammability. Oxygen index (OI) determines the inclination of materials to burn. The higher the value of oxygen index, the lower tendency of the smoking material, because it needs a larger amount of oxygen in its environment to the combustion process, was possible. Figure 8 summarizes oxygen index values of vulcanizates filled with different content and type of straw.

Flammability of the conventionally cross-linked natural rubber determined on the basis of the OI was $27.8 \%$. Oxygen index of composites with addition of straw was lower, at around $25 \%$, which represents a decrease of resistance to burning. The increase in filler content for all types of straw caused a marked decrease of OI and increase vulnerability to smoke generation. Biocomposites burned with an intense orange flame, additionally, during the burning sparks occurred.

\section{Thermo-oxidative aging processes}

Rubber products during exploitation are exposed to different environmental factors leading to their degradation. Increased temperature initiates aging of the vulcanizates, so it is important to investigate, how these materials react while introduced for this type of process. Determination of the composites resistance on thermooxidative aging was estimated on the basis of mechanical properties changes. The results of thermal aging factors for samples filled with different type of straw (0-50 phr) are given in Fig. 9.

Regardless of the type and the amount of filler used, all the vulcanizates proved to be resistant to thermo-oxidative degradation. This means no effect of aging on the mechanical properties of composites, which may be a positive aspect in terms of usability for this type of materials. 


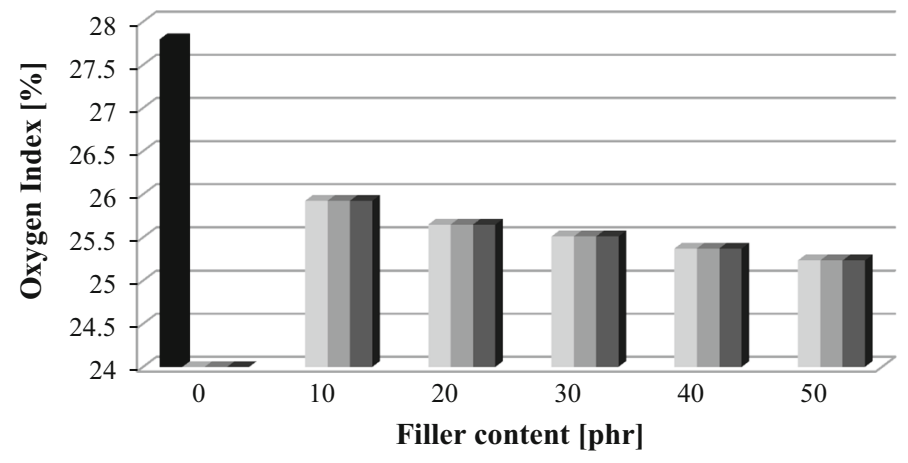

- Reference sample $\square$ Rye $\quad$ Oat $\square$ Triticale

Fig. 8 Effect of different straw fillers content on the oxygen index (OI) of the vulcanizates

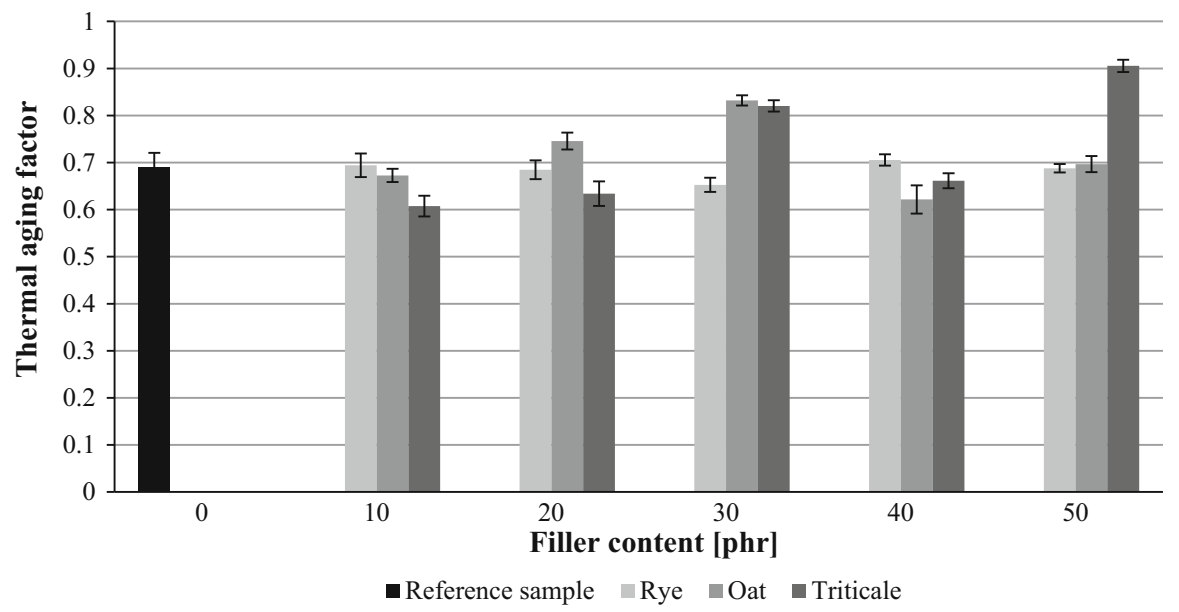

Fig. 9 Thermal aging factor of composites filled with different type of straw (0-50 phr)

\section{Barrier properties (air permeability) of NR vulcanizates}

Natural rubber is an important elastomer with a wide range of applications. However, clear natural rubber exhibits weaker barrier properties in comparison with other elastomers. From a practical point of view, it is undeniably essential to obtain composites with improved barrier properties. Influence of different straw fillers content and that on the barrier properties of the composites are given in Figs. 10, 11, and 12 .

At the beginning of the measurement for the reference sample was observed high air permeability as shown by high pressure expansion of the air in the chamber at the start of the investigation. During the examination, the permeability increased gradually. Finally, after $3 \mathrm{~h}$ of analysis, it reached 77 mbar of air pressure in the measuring chamber. That means, the vulcanizate did not reveal significant barrier 


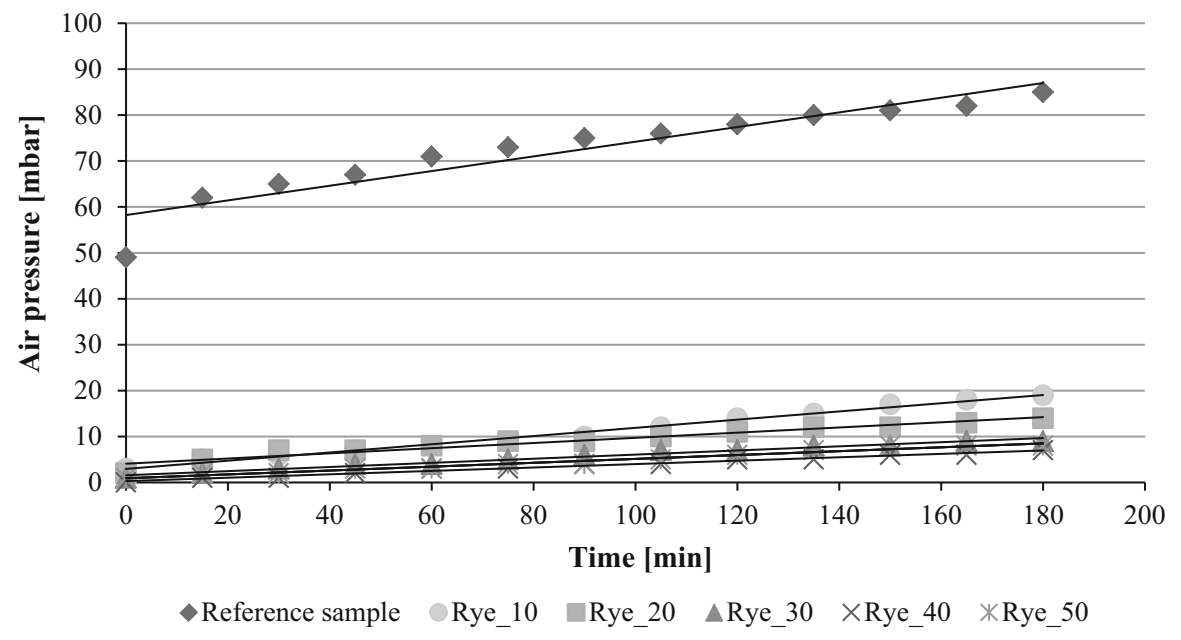

Fig. 10 Barrier properties (air permeability) of vulcanizates filled with rye straw (0-50 phr)

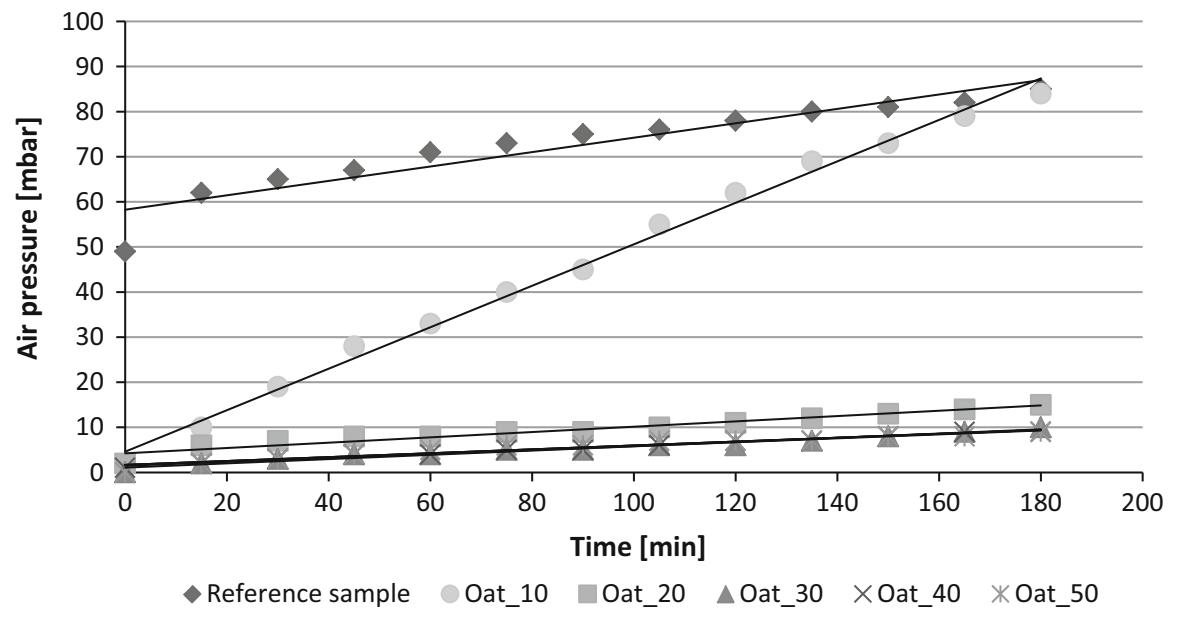

Fig. 11 Barrier properties (air permeability) of vulcanizates filled with oat straw (0-50 phr)

properties. Definitely, the use of straw as a filler for natural rubber reduces gas permeability. For all types of composites, pressure in the low-pressure chamber did not exceed 20 mbar. In general, with the increase of the filler content, a decrease in air permeability in natural rubber vulcanizates was observed, with one exception$10 \mathrm{phr}$ of oat straw. The probable cause of low gas permeability is strong restriction of the mobility of rubber chains by fine straw particles and also reducing the diffusion of the gas molecules. 


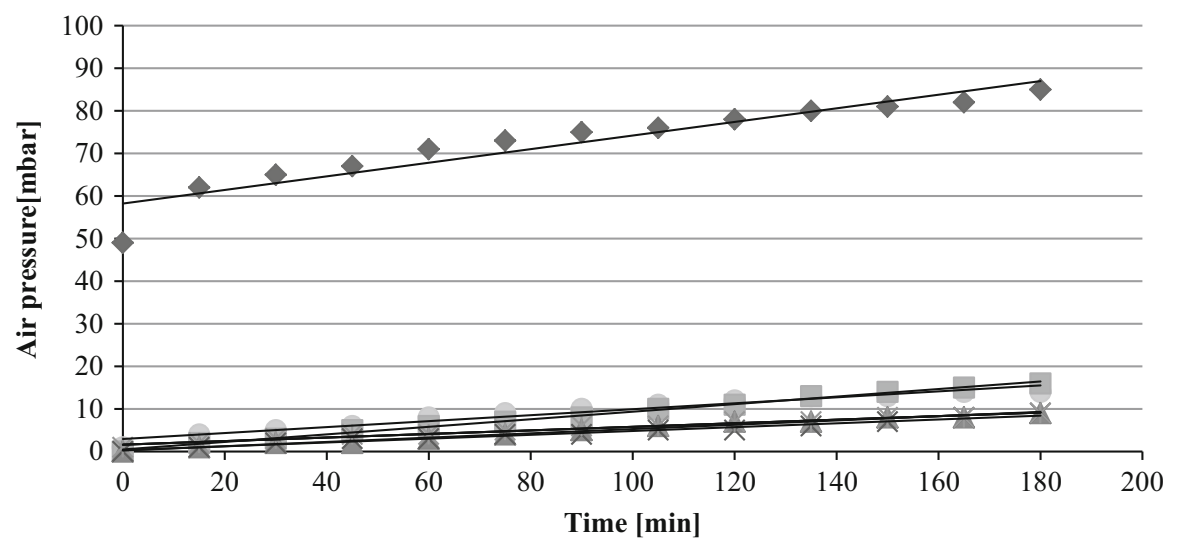

$\diamond$ Reference sample $\odot$ Triticale_10 Triticale_20 $\Delta$ Triticale_30 $\times$ Triticale_40 $*$ Triticale_50

Fig. 12 Barrier properties (air permeability) of vulcanizates filled with triticale straw (0-50 phr)

\section{Dynamic-mechanical properties of biocomposites containing straw fillers}

Payne effect depends on the existence and correctly destroyed secondary structure of the filler during dynamic measurements of vulcanizates. This important factor depends on the distribution of the filler particles in polymer matrix. Composites in which the particles are well dispersed exhibit low Payne effect. The results of dynamic-mechanical properties of biocomposites are given in Table 4.

The addition of fillers, despite of their type, to the elastomer increases the elastic modulus $\Delta G^{\prime}$ and loss modulus $G^{\prime \prime}$ which is probably caused by the formation of theirs own structure, so the filler "network" in the elastomer. The highest values of Payne effect-the most second-row complex structure of natural rubber vulcanizates-were determined for composites filled with oat and rye straw. Composite with the highest amount of filler proves the smallest decrease of the modulus. Increase of modulus is also associated with increasing the specific surface area and a higher complex structure of the filler. Moreover, dynamic-mechanical examinations confirm the results obtained for rheological properties and cross-linking density of composites. During the dynamic property measurements, a major impact on the reinforcing filler action in the elastomer has a surface energy. The slope of the stress-strain in the measurement is associated with the filler-polymer and a fillerfiller interactions.

\section{Conclusions}

Biocomposites were prepared by commonly used technics for elastomer technology-mixing natural rubber and straw fillers. Incorporation of lignocellulosic material into rubber resulted in obtaining composites with enhanced mechanical, barrier, and damping properties. 
Table 4 Influence of different straw fillers content on the increases the elastic modulus $\Delta G^{\prime}$ and loss modulus $G^{\prime \prime}$ of the compositions

\begin{tabular}{llll}
\hline Filler type & $\begin{array}{l}\text { Filler content } \\
{[\mathrm{phr}]}\end{array}$ & $\begin{array}{l}\Delta G^{\prime} \\
{[\mathrm{MPa}]}\end{array}$ & $\begin{array}{l}G^{\prime \prime}{ }_{\text {max }} \\
{[\mathrm{MPa}]}\end{array}$ \\
\hline Rye & 10 & 0.225 & 0.051 \\
& 20 & 0.323 & 0.079 \\
& 30 & 0.406 & 0.071 \\
& 40 & 0.548 & 0.106 \\
Oat & 50 & 0.549 & 0.116 \\
& 10 & 0.142 & 0.039 \\
& 20 & 0.382 & 0.075 \\
& 30 & 0.452 & 0.145 \\
Triticale & 40 & 0.629 & 0.116 \\
& 50 & 0.631 & 0.142 \\
& 10 & 0.169 & 0.027 \\
& 20 & 0.317 & 0.075 \\
& 30 & 0.406 & 0.083 \\
& 40 & 0.408 & 0.091 \\
& 50 & 0.495 & 0.124 \\
\hline
\end{tabular}

The addition of straw fillers caused an increase in torque during cross-linking, relative to the unfilled system. In addition, $\Delta M$ values increased with the higher content of the straw. This indicates the activity of biofillers which create "structure" in the elastomer and an increase of the hydrodynamic effect, which results in greater stress in the elastomer network. Semi-reinforced character of the fillers was confirmed via DBPA measurement. The use of lignocellulosic material resulted in a reduction of curing time to $2 \mathrm{~min}$.

The application of straw as a filler increased cross-linking density of vulcanizates, as reflected previously by the rheometric properties characterization. The presence of these fillers resulted in obtaining composites with good mechanical properties (tensile strength and elongation at brake) and hardness. The addition of $10 \mathrm{phr}$ of the fillers caused obtaining composites with the highest TS values, whereas further content increment reduced this parameter. However, the tensile strength of these vulcanizates is still acceptable for technological applications. Moreover, the use of straw as a polymer additive influenced the damping properties of composites.

Mechanical property analysis of vulcanizates subjected to the processes of thermo-oxidative aging indicates that biofillers did not cause deterioration of the mechanical properties of vulcanizates. Regardless of the used amount of filler, all the vulcanizates proved to be resistant to thermo-oxidative degradation. The application of straw as a filler resulted obtaining composites with lower value of oxygen index, that reflecting higher tendency of smoke generation.

In general, the addition of all types of natural fillers significantly reduced gas permeability. That can be explained with strongly restricted mobility of rubber chains by fine filler particles inhibiting the air penetration through the obtained rubber composites. 
The addition of straw, regardless of its type, to the elastomer increased the elastic modulus $\Delta G^{\prime}$ and loss modulus $G^{\prime \prime}$ which is likely related to the formation of their own, "network" in the elastomer.

Application of rye, oat, and triticale as biofillers for natural rubber composites indicates high application level of those types of materials, connected with significant multifunctional properties. In addition, ecological and economic benefits can be reached, solving typical agriculture problems with straw utilization.

Open Access This article is distributed under the terms of the Creative Commons Attribution 4.0 International License (http://creativecommons.org/licenses/by/4.0/), which permits unrestricted use, distribution, and reproduction in any medium, provided you give appropriate credit to the original author(s) and the source, provide a link to the Creative Commons license, and indicate if changes were made.

\section{References}

1. Zini E, Scandola M (2011) Green composites: an overview. Polym Compos 32:1905-1915. https:// doi.org/10.1002/pc.21224

2. Dufresne A (2008) Cellulose-based composites and nanocomposites. In: Gandini A, Belgacem MN (eds) Monomers, polymers and composites from renewable resources. Elsevier, Oxford, pp 401-418

3. Dufresne A (2008) Polysaccharide nano crystal reinforced nanocomposites. Can J Chem 86:484-494. https://doi.org/10.1139/v07-152

4. Azizi Samir MAS, Alloin F, Dufresne A (2005) Review of recent research into cellulose whiskers, their properties and their application in nanocomposite field. Biomacromol 6:612-626. https://doi. org $/ 10.1021 / \mathrm{bm} 0493685$

5. Habibi Y, Lucia LA, Rojas OJ (2010) Cellulose nanocrystals: chemistry, self-assembly, and applications. Chem Rev 110:3479-3500. https://doi.org/10.1021/cr900339w

6. Yu L, Dean K, Li L (2006) Polymer blends and composites from renewable resources. Prog Polym Sci (Oxford) 31:576-602. https://doi.org/10.1016/j.progpolymsci.2006.03.002

7. Nair AB, Joseph R (2014) Eco-friendly bio-composites using natural rubber (NR) matrices and natural fiber reinforcements. Chem Manuf Appl Nat Rubber 9:249-283. https://doi.org/10.1533/ 9780857096913.2.249

8. Haghighat M, Zadhoush A, Nouri Khorasani S (2005) Physicomechanical properties of-cellulosefilled styrene-butadiene rubber composites. J Appl Polym Sci 96:2203-2211. https://doi.org/10.1002/ app. 21691

9. Gopalan Nair K, Dufresne A (2003) Crab shell chitin whisker reinforced natural rubber nanocomposites. 1. Processing and swelling behavior. Biomacromolecules 4:657-665. https://doi.org/10.1021/ bm020127b

10. Siqueira G, Abdillahi H, Bras J, Dufresne A (2010) High reinforcing capability cellulose nanocrystals extracted from Syngonanthus nitens (Capim Dourado). Cellulose 17:289-298. https://doi.org/10. 1007/s10570-009-9384-z

11. Ben Thabet I, Francis F, de Pauw E et al (2010) Characterisation of proteins from date palm sap (Phoenix dactylifera $\mathrm{L}$.) by a proteomic approach. Food Chem 123:765-770. https://doi.org/10.1016/ j.foodchem.2010.05.024

12. Wang Y, Tian H, Zhang L (2010) Role of starch nanocrystals and cellulose whiskers in synergistic reinforcement of waterborne polyurethane. Carbohyd Polym 80:665-671. https://doi.org/10.1016/j. carbpol.2009.10.043

13. Favier V, Chanzy H, Cavaille J-YY (1995) Polymer nanocomposites reinforced by cellulose whiskers. Macromolecules 28:6365-6367

14. Sarnklong C, Coneja JW, Pellikaan W, Hendriks WH (2010) Utilization of rice straw and different treatments to improve its feed value for ruminants: a review. Asian Aus J Anim Sci 23:680-692. https://doi.org/10.5713/ajas.2010.80619

15. Antongiovanni M, Sargentini C (1991) Variability in chemical composition of straws. Option Méditérranéennes 16:49-53 
16. Viola E (2008) Processing cereal straws by steam explosion in a pilot plant to enhance digestibility in ruminants. Bioresour Technol 99:681-689. https://doi.org/10.1016/j.biortech.2007.02.001

17. Matsumura Y, Minowa T, Yamamoto H (2005) Amount, availability, and potential use of rice straw (agricultural residue) biomass as an energy resource in Japan. Biomass Bioenerg 29:347-354. https:// doi.org/10.1016/j.biombioe.2004.06.015

18. Patil SK (2008) Functional cereal products for those with gluten intolerance. Technol Func Cereal Prod. https://doi.org/10.1533/9781845693886.2.495

19. Paukszta D (2006) Skład chemiczny zdrewniałej części łodygi słomy rzepakowej. Rośliny Oleiste 28:143-150

20. Bueche AM (1957) Filler reinforcement of silicone rubber. J Polym Sci 25:139-149. https://doi.org/ 10.1002/pol.1957.1202510902 